\title{
Construction and Metabolism of Cultural Landscapes for Sustainability in the Anthropocene
}

\author{
Diego Subercaseaux ${ }^{1,2,3,4}$, Juan Gastó ${ }^{1}$, José Tomás Ibarra ${ }^{5,6,7}$ (D) and \\ Eduardo C. Arellano 1,7,8,*iD
}

1 Facultad de Agronomía e Ingeniería Forestal, Pontificia Universidad Católica de Chile, Santiago 7830436, Chile; dsuberca@uc.cl (D.S.); jgasto@uc.cl (J.G.)

2 National School of Higher Studies (ENES), Universidad Nacional Autónoma de México (UNAM), Morelia 58190, Mexico

3 Posgraduate in Sustainability Science, Universidad Nacional Autónoma de México (UNAM), Morelia 58190, Mexico

4 Transdisciplinary Center for FES-Systemic Studies (CTF), Padre Mariano 391 Oficina 704, Providencia Santiago 7500017, Chile

5 ECOS (Ecology-Complexity-Society) Laboratory, Center for Local Development (CEDEL) \& Center for Intercultural and Indigenous Research (CIIR), Villarrica Campus, Pontificia Universidad Católica de Chile, Villarrica 4930000, Chile; jtibarra@uc.cl

6 Millennium Nucleus Center for the Socioeconomic Impact of Environmental Policies (CESIEP), Pontificia Universidad Católica de Chile, Santiago 7820244, Chile

7 Center of Applied Ecology and Sustainability (CAPES), Santiago 7820244, Chile

8 Centro Interdisciplinario de Cambio Global, Pontificia Universidad Católica de Chile, Santiago 7810000, Chile

* Correspondence: eduardoarellano@uc.cl

Received: 25 June 2020; Accepted: 1 August 2020; Published: 5 August 2020 updates

\begin{abstract}
In the Anthropocene, humans have become the dominant force behind the transformation of the planet and its cultural landscapes. In recent decades, there has been a paradigm shift in the sciences, changing the focus from the study of separate components to the study of wholes. In light of this, several fields of study have attempted to address the dichotomous paradigm of nature versus society by developing integrative concepts, such as 'social metabolism', to explain the inextricable interrelations between nature and society for building a sustainable future. In this paper, we examine the metabolism of cultural landscapes, considering the actions of social actors in their territories. Cultural landscapes emerge from the artificialization of nature and the opening of the land, resulting in a landscape that conforms to the culture and the availability of technologies, thus creating a whole system with either higher or lower levels of life quality and sustainability. Three central elements operate interactively in the construction of cultural landscapes: the territory, the social actors who act in the territory, and the articulators (e.g., technology and regulations). The construction of cultural landscapes gives rise to a gradient of territorial typologies, including wildland, rural and urban, which have different requirements and consumption of resources and energy. In the Anthropocene, many cultural landscapes have been constructed in such a way that they require and consume increasing amounts of energy. We describe carrying capacity, polycentricity, and Universal Lawfulness as three of the main considerations for the design of sustainable cultural landscapes.
\end{abstract}

Keywords: carrying capacity; complexity; nature artificialization; polycentricity; universal lawfulness; landscape design; social metabolism 


\section{Introduction}

In the Anthropocene, humans have become the dominant force behind the transformation of territories and the construction of cultural landscapes [1,2]. Territorial problems and the increasing degradation of social-ecological systems demonstrate, however, that we may lack the capacity to properly direct this force in order to construct landscapes that last over time [3,4]. A landscape, as part of a worldview, is produced intellectually and materially by a certain social group [5]; a cultural landscape can be considered as a complex geographic reality, existing in historical time, that functions as a system of energy, material, and information flow interwoven in real, perceived, and symbolic ways [6]. It has been increasingly acknowledged that whole-system approaches are required to inform national and international agendas dealing with climate change, social-ecological degradation, and poverty in the Anthropocene [7]. Such whole-system approaches should overcome epistemological barriers between the natural sciences, social sciences, and the humanities, and deal with techno-economic and political realms in which decisions concerning territories are implemented [8].

In the last 50 years, a paradigm shift has occurred in science with the emergence of the paradigm of complexity [9], and so-called complexity science, in which the study object evolved from separate components to a focus on the whole [10-12]. This shift has meant that many researchers no longer focus on linear and deterministic processes but rather on self-organized networks of interactive actors that give rise to complex systems [13-15]. This approach tried to overcome the limitations of mainstream scientific knowledge, which posits the objectivity of scientific truths, acknowledging the need for a comprehensive and contextual approach dealing with uncertainties $[8,10,16,17]$. This paradigm shift also allowed addressing issues such as human social learning based on intentional and adaptive collective cognition in the construction of sustainable cultural landscapes $[3,8,18,19]$. During the last decades, researchers from different fields have nurtured the theory, principles, and methodologies of complexity science and its applications. Morin [9], for example, proposed a general theory of complexity for contemporary science; Capra [20] proposed understanding life as networks of relationships at different levels; Padua [21] defined environmental history as an open, non-reductionist investigation of the interrelationships between social and natural systems over long periods of time. The concept of the cultural landscape is a whole-system study object, fundamental to comprehensively understand current transformations and evolutionary dynamics of territories [22,23].

Several other authors have used the concept of social metabolism to explain the relations between society and nature [24,25]. For example, some scholars have placed social metabolism at the heart of the analysis concerning the main driving forces of land-use change [22,26]. Social metabolism attempts to explore a particular system at a given historical moment, together with its social, ecological, and physical dimensions [24]. Sociometabolic research is a systems' approach to study nature-society relations at different spatiotemporal scales. It is based on the assumption that nature and people are coupled complex systems that reproduce themselves, interact with each other, and co-evolve over time $[7,27]$. The impact of social metabolism has grown exponentially since the 1990s, being used by many authors of different scientific disciplines. In recent years, other related concepts have emerged such as anthropospheric metabolism, urban metabolism, socio-ecological metabolism, socio-economic metabolism, agrarian metabolism, and rural metabolism (e.g., [7]). Similarly, other concepts have been coined based on scale, such as local, regional, national, and global metabolism [25]. Recently, social metabolism has been at the core of academic and political debates concerning sustainability [25].

The objective of this paper is to put forward a discussion on the construction and metabolism of cultural landscapes, that is, their emergence from the artificialization of nature. This discussion is developed with a territory perspective and a framework of complexity, incorporating the actions of social actors in their territories. We start by explaining how cultural landscapes and different territorial typologies emerge from the process of artificialization of nature. Then, we introduce the metabolism of cultural landscapes and its application to human societies, along with the use of this concept in nature-society studies. In this section, we further describe the link between social metabolism and 
the laws of thermodynamics. Finally, we describe critical considerations for the design of sustainable cultural landscapes in the Anthropocene.

\section{Artificialization and the Construction of Cultural Landscapes}

Artificialization is the transformation of nature by human interventions, causing a different and dynamic state of the ecosystem and its natural components (e.g., soil, water, trees, or a forest, meadow, mountain range, coastal border). The result of artificialization is cultural landscapes, which are different from the most likely state that the ecosystem would have achieved without human intervention. Throughout human history, the prevailing trend has been the intensification of the artificialization of nature. The development of agriculture and the subsequent emergence and construction of the first cultural landscapes took place around 11,000 years ago, when humans started tilling the land and farming cereal grains and other cultivars, marking the beginning of the expansion of the anthropogenic border [28].

The artificialization of nature is facilitated by the action of operators (i.e., the necessary stimulus in a system to change from one state to another in a certain period) with a certain amount of work and a certain probability of success [29]. The process of artificialization is geared toward the conquest of niches and the optimization of the anthropogenic channeling of goods and services, extracting and incorporating elements into the ecosystem, often simplifying it structurally and functionally [1]. Three elements interact in the process of constructing a cultural landscape: the territory with its natural and anthropogenic components, the social actors who act in the territory, and the articulators (e.g., technology and regulations) of the interaction between the two previous elements. The characteristics of these three elements differ between societies, according to their own cultures and local ecosystems, giving rise to a diversity of cultural landscapes in the world. A cultural landscape, in its space-time territorial expression, can be represented symbolically as:

$$
\mathrm{P}=\mathrm{f}(\mathrm{S}, \Sigma, \phi, \sigma \mathrm{a})
$$

where:

$\mathrm{S}$ is space-time;

$\Sigma$ is territorial units with social actors inhabiting and acting there;

$\phi$ is flows within each territorial unit and between the territorial units;

$\sigma a$ is the system's total response (output).

Each society establishes a relation of mutual adaptation with local nature [30,31] within the complementary processes of humanization (artificialization) of nature and naturalization of the human [32]. Naturalization is the reverse process of artificialization in the construction of cultural landscapes. Both processes, artificialization and naturalization, interact and complement each other, with relative magnitudes of each varying across territorial typologies: wildland, rural, and urban (Figure 1). These territorial typologies are differentiated by the varying proportions of three territorial components, including saltus, ager, and polis. Saltus is the territorial component that is not directly affected by anthropogenic actions; ager is the spatially open territorial component with a moderate degree of anthropogenic artificialization (i.e., "farming" as a predominant style of artificialization); and polis is the territorial component with a high degree of artificialization (i.e., "infrastructures" as the predominant style of artificialization) [1]. With the construction of a cultural landscape, a specialization of the territory takes place and a gradient of different territorial typologies arise [33]. 


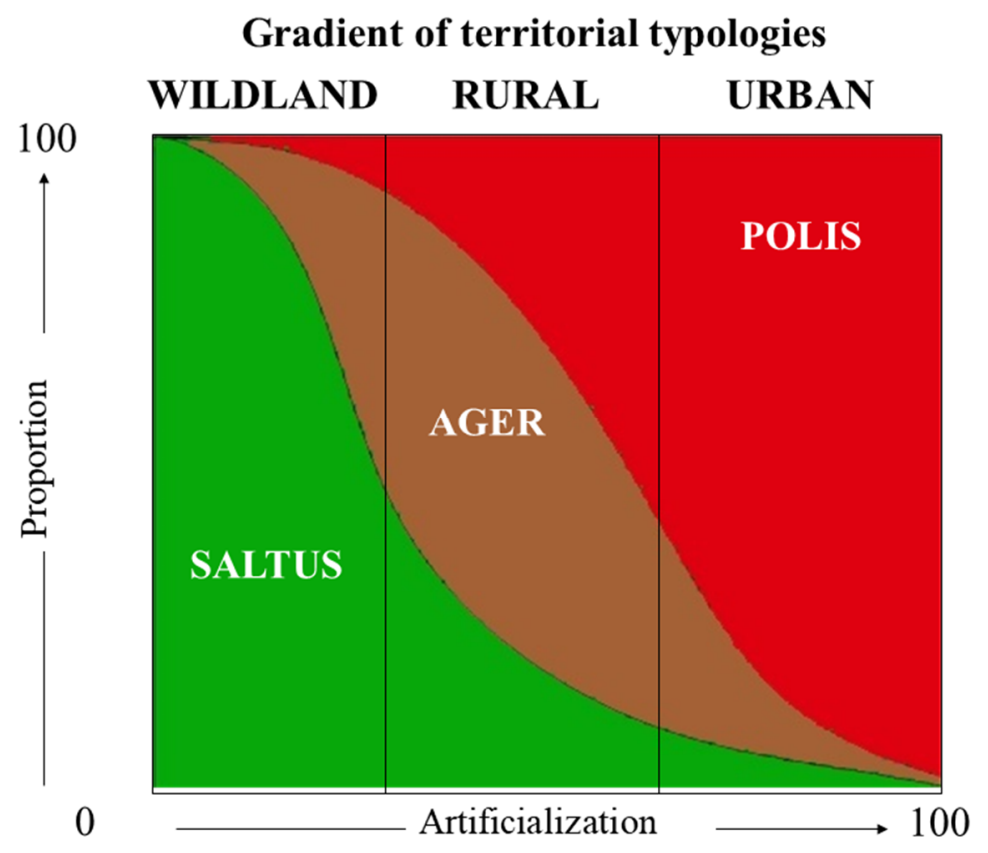

Figure 1. Relative proportions of saltus, ager, and polis, which are characteristic of the gradient of the territorial typologies' wildland, rural, and urban according to the degree and type of artificialization. Saltus is the territorial component without extensive transformation by anthropogenic actions; ager is the spatially open territorial component with a moderate degree of anthropogenic artificialization; and polis is the territorial component with a high degree of artificialization (adapted from [1]).

\section{Metabolism of Cultural Landscapes}

The cultural landscape organizes itself in a process of artificialization, resulting in a complex system that is far-from-equilibrium. The theory of dissipative structures [20,34,35], explores the dynamics of such systems, in which order and disorder complement each other [34]. Dissipative structures correspond to situations in which the dissipation of energy in the system can provide clues for a local order at the expense of the growing chaos in its environment. At the same time, total entropy keeps increasing according to the second law of thermodynamics [20,34]; in this way, the order "floats in disorder". For example, living organisms take ordered structures (food) from their environment, use them as resources for their metabolic processes, and dissipate lower-order structures (waste) into the environment. Living organisms are constantly kept in a state that is far-from-equilibrium but stable, maintaining their general structure despite the incessant flow and change of components. Prigogine's concept of dissipative structure includes the idea of points of instability and bifurcation, in which the behavior of the system is unpredictable and depends in part on its history. These instabilities can lead to the spontaneous emergence of new forms of order, that is, self-organization [20]. Prigogine's theory of dissipative structures provides a theoretical basis to explain the socio-cultural dynamics and mutations that seemed inexplicable in terms of energy flow or the effect of adding instability to human ecosystems [36]. Moreover, a condition that is far-from-equilibrium will be associated with a more significant potential for innovation, and thus a greater potential for adaptation [37].

In biology, metabolism involves the sum of all the physical-chemical processes that occur within a living organism. A parallel can be drawn with human social systems in terms of the reproduction of societies, their economic production, and the consumption processes that require flows of matter and energy. Fischer-Kowalski [38] used the term social-economic metabolism to describe the material and energy flows between society and nature. This author stresses that these processes are subject to the laws of thermodynamics and other physical limitations, including the availability of space [24]. In the 1990s, the concept of social metabolism became formalized within the framework of social-environmental 
studies [25]. In practice, social metabolism established a new approach to the study of nature-society relationships, primarily through the study of energy and material flows $[25,27,39-42]$. By focusing on the metabolism of a specific society, the so-called externalities no longer correspond to sporadic market failures or failures of government actions but acquire instead an unavoidable systemic character [42]. The study of the social metabolism helps to understand the history and development of cultural landscapes in the present and in the past [24,43]. Furthermore, the social metabolism approach is useful for addressing hybrid problems and for conducting transdisciplinary research in a complexity science framework $[25,44,45]$.

The societies that have existed throughout human history have exhibited various energy consumption patterns [24]. For example, Tyler [45] divided human history into several ages and estimated the average direct and indirect daily energy consumption per person. For each one of these ages, the estimates of kilocalories/person/day were as follows: primitive society, 2000 kilocalories/person/day; hunter-gatherers, 5000 (both during approx. 30,000 years BC); early agricultural age (around 10,000 BC), 12,000; advanced agricultural age (7000 BC), 20,000; early industrial age (from the 18th century), 60,000; modern industrial age (20th century), 125,000; USA-style modern industrial age (20th century), 230,000. Two unusually large increases in average energy consumption per person can be observed, related to the shift to an "industrial metabolism". First, with the shift from the agricultural age to the early industrial age, consumption tripled. Then again, with the shift from the early industrial age to the modern industrial age, consumption increased a little more than double. It should also be noted that this last step took place in less than two centuries and involved a significant increase in human population size and density. There are long-term studies that attempt to document the transition in agriculture from pre-industrial to industrialized management [25]. The development of articulators of artificialization has led to increased energy consumption, such as the introduction of metal plows, animal traction, fertilizers, agricultural and rural works, and infrastructure.

The way that social actors act in the ecosystem through artificialization, and thus how a cultural landscape is constructed, has implications for its metabolism. The metabolism varies between the typologies of the territory (wildland, rural, and urban) as these have their specific characteristics in terms of culture, lifestyle, population density, and technological level, resulting in different requirements and consumption of resources and energy. The relative proportions of saltus, ager, and polis in the various territories result in different metabolisms and energy consumption.

We propose that the metabolic energy load of a cultural landscape (i.e., the energy it requires for its functioning) is primarily determined by the number of inhabitants of the territory and their average energy consumption. The energy consumption will be determined by the lifestyle of the inhabitants and the technology that exists in the territory, as described below:

$$
\mathrm{K}=\mathrm{NP} * \mathrm{CMP} * \mathrm{NT}
$$

where:

$\mathrm{K}$ is Metabolic load of the cultural landscape

NP is Number of people

CMP is Metabolic cost per person

NT is Technological level

The metabolism of a human society embraces the laws of thermodynamics for social exchanges; energy and matter are transformed, broken down, and re-organized for other uses, forming the so-called ecological pyramids [24]. For example, the flow chart that schematically depicts the energy transformations of an agricultural system from primary production to final consumption is a balance sheet that complies with the following laws: (1) the total amount of primary energy produced by human labor in an agroecosystem cannot be increased or decreased, only transformed; (2) in each transformation there is a loss in the form of heat, increasing entropy and thus reducing the useful energy that can be used to carry out a task, through the losses derived from bio-conversion or combustion. These two laws require a continuous input of energy into the system, whose flow originates from solar 
energy in the case of ecosystems [24]. The second law provides the key to understanding the efficiency of the system by comparing the primary energy input to the proportion that can be consumed by human societies [26]. A relevant point to understand social metabolism is how the laws of thermodynamics relate to the physical space. According to the second law of thermodynamics, entropy increases together with the number of possible paths resulting from the growing complexity of the system and its spatial-territorial expansion [46].

It has been argued that the law of entropy is non-deterministic. This is important because, without entropy, it would be impossible for humans to "reverse" high to low entropy and for innovation to take place $[47,48]$. Therein lies the crucial role of technical, organizational, and cultural innovation in improving the efficiency of the entire chain of processes to satisfy human needs, requiring someone to envision ways in which to improve a particular exosomatic matrix [49]. From a biophysical perspective, what economics dubs as "production" is, in fact, a succession of energy and material transformations that allow primary resources with a high "useful task" or "exergy" potential to be converted into other materials and forms of energy of lower exergy but higher economic value. This conversion entails the "physical cost" of the total loss of "useful energy" (or exergy) generated by the transformations as a whole, whereby a greater or lower degree of this physical cost depends on the system's energy and material efficiency [50]. Technology should aim to increase energy efficiency in production and economic processes in general, as well as in social metabolism. In other words, the economic value must be achieved by reducing the physical cost, minimizing the loss of useful energy or energy potential to perform a particular task (exergy).

The current trend of constructing cultural landscapes whose functionality is mainly economic, which is linked to the predominance of economic rationality, the prevailing economic model, and technocracy, has resulted in significant implications for the metabolism and unsustainability of these systems [48]. When agriculture economies ceased to be organic, large amounts of external inputs were increasingly added to human labor. More than thirty years ago, it became evident that the increase in final energy obtained with the growing number of external inputs associated with the so-called green revolution in agriculture was much lower than its energy cost [50]. The transformation turned into a reduction rather than an improvement in the energy efficiency of the global agricultural and food system [26,51-53]. That is to say, how rural cultural landscapes have usually been constructed since the middle of the last century has led to a more energy-inefficient metabolism.

Different schools of thought in sociometabolic research have focused mainly on studying the same underlying process, that is, society's use of biophysical material and energy resources [7]. However, they have barely incorporated the sociocultural dimension, which, as shown in this article, is a critical factor in the construction of cultural landscapes and the transformation and evolution of the territories. Thus, some variables with high explanatory power have been poorly incorporated into the study of the metabolisms of different societies, such as power relations and conflicts between social actors. The school developed mainly by Toledo and González de Molina has addressed such sociocultural dimensions in-depth (e.g., [27]). The approach of the metabolism of cultural landscapes considers the sociocultural dimension and is adequate to better critically understand, for example, power relations and conflicts between social actors over a territory. Efforts to explicitly link sociometabolic research to other social science studies can be strengthened for linking social metabolism with the behavior of social actors in the emerging fields of sustainability transformation research [7].

\section{Considerations for the Design of Sustainable Cultural Landscapes}

\subsection{Carrying Capacity of the System}

The carrying capacity is a system's limited ability to support or sustain a certain activity, considering all the involved structures and processes. Therefore, the carrying capacity of the cultural landscape corresponds to the system's limited capacity to support or sustain the activities of the social actors in 
the territory, with their respective technological level, resource consumption, and waste generation, all of which occur within a specific cultural context.

There is now ample evidence that oftentimes the actual territorial payload exceeds the respective carrying capacity. The real payload on the territories, and more precisely the difference between it and its respective carrying capacity, generates a pollution that is greater than that which the ecosystem and the cultural landscape can assimilate. This generates a residual pollution that gradually accumulates, which is unsustainable. In metabolic terms, this real payload is determined and explained by the above-mentioned variables determining the metabolic payload of the cultural landscape: number of people, metabolic cost per person (energy), and technological level. Moreover, the current metabolism of the most industrialized societies could not be sustained without the natural resources of the less industrialized, commodity-supplying societies at low prices; in which case, their environmental costs in the context of social-ecological inter-territorial relations and unequal economic-ecological exchange must be considered $[25,54]$.

The prevailing pattern in which many cultural landscapes have been constructed usually entails their simplification. The simplifying effect of human influence on the structure of cultural landscapes has important ecological consequences $[55,56]$. Niches are simplified and often extinguished, which poses a problem for biological diversity as well as for ecological processes and the provision of ecosystem services. Moreover, it leads to a decline in the potential for ecological restoration and resilience and a loss of adaptive capacity [48]. The adaptive capacity and resilience of a complex system are conditioned mainly by its carrying capacity and the actions of social actors, which are both key for designing sustainable cultural landscapes.

\subsection{Polycentricity and Universal Lawfulness}

An intentional construction of the cultural landscape entails comprehensive design as a basic operator to steer the landscape toward a desired state. We now need to actively increase ecosystem and territorial services; our task is not only to conserve but also to design and build [8] using a dynamic, intentional, and collective integrated management.

In order to sustainably develop the territory, it is essential to design it by creating several medium-sized population centers that provide the right conditions for self-sufficiency and quality of life, well-being, and sustainability, rather than developing large cities that operate as territorial hubs, thereby fostering a center-outskirts dichotomy with asymmetric relations between the two. Designing territories with small and medium-sized villages, with a polycentric approach and a collective and participatory design, is metabolically more efficient than a centralist approach and design. The concept of polycentricity [57] implies multiple decision-making centers that act somewhat independently. It is opposed to the idea that having many government units without a clear hierarchy is chaotic. A polycentric territorial design allows for more sustainable urban territories and more symmetrical relations between them and rural and wild territories. Maintaining the self-organization of nature, as well as the construction of sustainable anthropogenic systems, cannot be achieved through centralized management [58]; it requires localized and interconnected design and management. The theory of non-linear systems far-from-equilibrium and dissipative structures shows and supports the importance of local phenomena in the cultural landscape and thus of the development and evolution of bottom-up forces.

In general, the design of cultural landscapes seeks to manage the system's structure and spatially distribute human activities. It aims to establish the best combination of these activities in the territory according to the needs of society in terms of its culture on the one hand and ecological potentials and constraints on the other. The objective of the design of sustainable cultural landscapes should be to maximize the quality of life of the territory's inhabitants (1). This design must consider and incorporate the concept of "Universal Lawfulness", which integrates the restrictions of the physical and ecological levels for the management of and decision-making on social, technological, economic, and political aspects in a territory (Figure 2) [1,59]. We must consider Universal Lawfulness as a basic 
and guiding consideration when assessing the metabolism of the cultural landscape and of any system that is produced through the artificialization of nature.

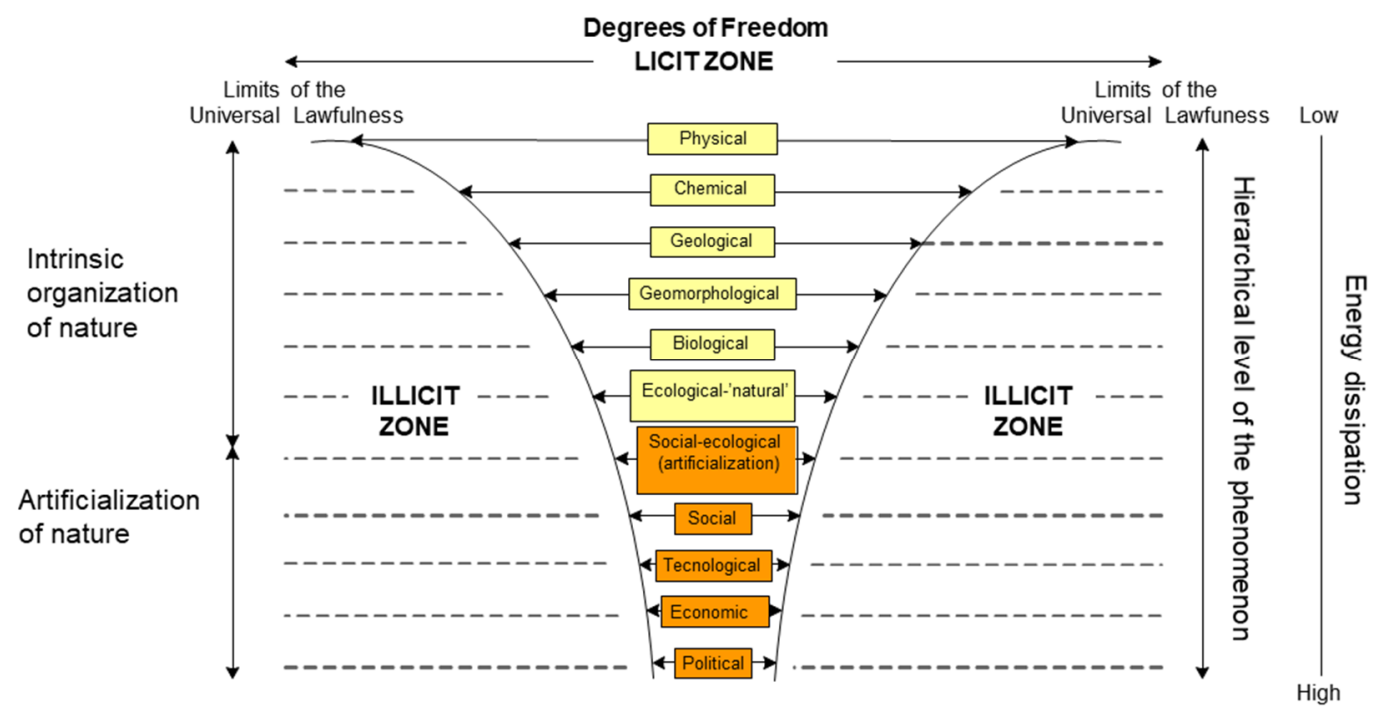

Figure 2. Generalized hierarchical structure and its degrees of freedom according to Universal Lawfulness (adapted from [1]). Sustainable cultural landscapes should be designed within the licit zone across all the hierarchical levels (from higher to lower) of the Universal Lawfulness.

Ecosystem vulnerability must be considered in the design for the sustainability of cultural landscapes. In a highly vulnerable ecosystem, the additional maintenance costs needed to secure ecosystem sustainability are greater than the benefits of artificialization for any level of technological intensity, so that any artificialization is considered "illicit" (i.e., unsustainable; Figure 2). However, by acting under a merely exploitative logic, only the unavoidable ecological costs of harvest for the extraction of resources are absorbed, but the additional maintenance costs for ecosystem sustainability are not. In this case, the artificialization is illicit because it produces an unsustainable cultural landscape. When deterioration of the system's resources and services occurs, it will later be abandoned. This is often the case, for example, with deforestation by clear-cutting and intensive fruit orchards on steep slopes [28].

\section{Conclusions}

We have shown that social metabolism helps to understand complex social-ecological systems in the process of artificialization of nature for the construction of cultural landscapes. The territory, social actors who act in the territory, and articulators (e.g., technology and regulations) are the three elements that interact in the construction of cultural landscapes. The construction of cultural landscapes gives rise to a gradient of territorial typologies, including wildland, rural and urban, which have different requirements and consumption of resources and energy. We highlighted that the metabolic energy load of a cultural landscape (i.e., the energy it requires for its functioning) is primarily determined by the number of inhabitants of the territory and their average energy consumption. Throughout the historical evolution of cultural landscapes, and especially in the Anthropocene, we can observe that many have been constructed in such a way that they require and consume increasing amounts of energy over time. Indeed, there has been an increasing simplification of cultural landscapes, with detrimental consequences such as loss of the potential for their resilience and adaptive capacity. In a context of crucial social-ecological changes, as is the case today, the adaptive capacity and resilience of cultural landscapes are key to sustainability.

The approach of the metabolism of cultural landscapes, with a territorial perspective which incorporates the actions of social actors and their cultural contexts, may be operational to promoting 
sustainability. For this, carrying capacity, polycentricity, and Universal Lawfulness are three important considerations for the design of cultural landscapes. A major challenge is putting these considerations on the political agenda and building multi-level governance to promote sustainability in the Anthropocene.

Author Contributions: Conceptualization, D.S. and J.G.; validation, D.S., J.G., E.C.A., and J.T.I.; investigation, D.S.; resources, D.S., J.G., J.T.I., and E.C.A.; writing—original draft preparation, D.S. and J.G..; writing-review and editing, D.S., J.G., J.T.I., and E.C.A. All authors have read and agreed to the published version of the manuscript.

Funding: This research received no external funding.

Acknowledgments: We would like to show our gratitude to all the graduate and undergraduate students, professionals, and friends that contributed with different thoughts through many years at Juan Gasto's territory lab. E.C.A. and J.T.I thank ANID PIA/BASAL FB0002 for funding. E.C.A. acknowledges the support from ANID/PIA/act192027. J.T.I. acknowledges the support from ANID/Fondecyt Regular (1200291), ANID/FONDAP/15110006, and ANID—Millennium Science Initiative-Center for the Socioeconomic Impact of Environmental Policies, CESIEP Code NCS13_004.

Conflicts of Interest: The authors declare no conflict of interest.

\section{References}

1. Gastó, J.; Subercaseaux, D.; Vera, L.; Tomic, T. Agriculture and rurality as constructor of sustainable cultural landscape. In Landscape Planning; Murat, O., Ed.; In Tech: Rijeka, Croatia, 2012; pp. 151-176.

2. Crutzen, P.J.; Stoermer, E.F. The "Anthropocene". Glob. Chang. Newsl. 2000, 41, 17-18.

3. Lubchenco, J. Entering the century of the environment: A new social contract for science. Science 1998, 279, 491-497. [CrossRef]

4. Walker, B.; Holling, C.S.; Carpenter, S.R.; Kinzig, A. Resilience, adaptability and transformability in social-ecological systems. Ecol. Soc. 2004, 9, 5. [CrossRef]

5. Fernández Christlieb, F. Geografía Cultural. In Tratado de Geografía Humana; Hiernaux, D., Lindón, A., Eds.; Anthropos Editorial y Universidad Autónoma Metropolitana-Iztapalapa: Barcelona, Spain; Iztapalapa, Mexico, 2006; pp. 220-253.

6. Terkenli, T. Towards a Theory of the Landscape: The Aegean Landscape as a Cultural Image. Landsc. Urban Plan. 2001, 57, 197-208. [CrossRef]

7. Haberl, H.; Wiedenhofer, D.; Pauliuk, S.; Krausmann, F.; Müller, D. Fischer-Kowalski, M. Contributions of sociometabolic research to sustainability science. Nat. Sustain. 2019, 2, 173-184. [CrossRef]

8. Röling, R. Gateway to the Global Garden: Beta/Gama Science for Dealing with Ecological Rationality. In Eight Annual Hopper Lecture; University of Guelph: Guelph, ON, Canada, 2000.

9. Morin, E. El problema epistemológico de la complejidad; Publicaciones Europa-América: Lisboa, Portugal, 2002; ISBN 9721018228.

10. Naveh, Z. What is holistic landscape ecology? A conceptual introduction. Landsc. Urban Plan. 2000, 57, 269-284. [CrossRef]

11. Wu, J. Landscape sustainability science: Ecosystem services and human well-being in changing landscapes. Landsc. Ecol. 2013, 28, 999-1023. [CrossRef]

12. Luc, M. Placing the idea of sustainable landscape in ecophilosophy. Probl. Ekorozw. Probl. Sustain. Dev. 2014, 9, 81-88.

13. Levin, S.A. Ecosystems and the biosphere as complex adaptive systems. Ecosystems 1998, 1, $431-436$. [CrossRef]

14. Strogatz, S.H. Exploring complex networks. Nature 2001, 410, 268-276. [CrossRef]

15. Ibarra, J.T.; Cockle, K.L.; Altamirano, T.A.; Van der Hoek, Y.; Simard, S.; Bonacic, C.; Martin, K. Nurturing resilient forest biodiversity: Nest webs as complex adaptive systems. Ecol. Soc. 2020, 25, 27. [CrossRef]

16. Gell-Mann, M. El Quark y el Jaguar. Aventuras en lo simple y lo Complejo; Tusquets Editores SA: Barcelona, España, 1995.

17. Wu, C.; Isaksson, K.; Antonson, H. The struggle to achieve holistic landscape planning: Lessons from planning the E6 road route through Tanum World Heritage Site, Sweden. Land Use Policy 2017, 67, 167-177. [CrossRef]

18. Vitousek, P.; Mooney, H.; Lubchenco, J.; Melillo, J. Human domination on Earth's systems. Science 1997, 277, 494-499. [CrossRef] 
19. Ostrom, E. A general framework for analyzing sustainability of social-ecological systems. Science 2009, 325, 419-422. [CrossRef] [PubMed]

20. Capra, F. The Web of Life. A New Synthesis of Mind and Matter; Harper Collins Publishers: London, UK, 1996; 359p.

21. Padua, J. As bases teóricas da história ambiental. Estudos Avanzados 2010, 24, 81-101. [CrossRef]

22. Vos, W.; Meekes, H. Trends in European cultural landscape development: Perspectives for a sustainable future. Landsc. Urban Plan. 1999, 46, 3-14. [CrossRef]

23. Luis-Calabuig, E. “Prólogo de la edición española”. In Ecología del Paisaje: Conceptos, Métodos y Aplicaciones; Burel, F., Baudry, J., Eds.; Ediciones Mundi-Prensa: Paris, France, 2002; pp. 15-16.

24. Stingel Fraga, J.; Ribeiro de Oliveira, R. Social metabolism, cultural landscape, and social invisibility in the forests of Rio de Janeiro. In Polyphonic Anthropology, Theoretical and Empirical Cross-Cultural Fieldwork; Canevacci, M., Ed.; InTech Open Access Publishers: Reijka, Croatia, 2012; pp. 139-156.

25. Infante-Amate, J.; González de Molina, M.; Toledo, V. El metabolismo social. Historia, métodos y principales aportaciones. Revista Iberoamericana Economía Ecológica 2017, 27, 130-152.

26. Tello, E.; Garrabou, R.; Cussó, X.; Olarieta, J. Una interpretación de los cambios de uso del suelo desde el punto de vista del metabolismo social agrario. La comarca catalana del Vallès, 1853-2004. Revista Iberoamericana Economía Ecológica 2008, 7, 97-115.

27. González de Molina, M.; Toledo, V.M. The social metabolism. In A Socio-Ecological Theory of Historical Change; Springer: New York, NY, USA, 2014.

28. Vera, L.; Gastó, J. Expansión de la frontera homínida en el paisaje cultural. In Hominización, Restauración y Gobernanza de la Cordillera de Los Andes de la Araucanía, Chile; Editorial Académica Española: Saarbrücken, Germany, 2011; 388p.

29. Nava, R.; Armijo, R.; Gastó, J. Ecosistema. In La Unidad de la Naturaleza y el Hombre; Editorial Trillas: Col. Mexico DF, México, 1996.

30. Nietschmann, B.Q. The Interdependence of Biological and Cultural Diversity; Center of World Indigenous Studies: Washington, DC, USA, 1992.

31. González-Jácome, A. Ambiente y Cultura en la Agricultura Tradicional de México: Casos y Perspectivas. Ergo Sum 2004, 11, 153-163.

32. Toledo, V.M.; Alarcon-Cháires, P. (Eds.) Tópicos bioculturales. In Reflexiones Sobre el Concepto de Bioculturalidad y la Defensa del Patrimonio Biocultural de México; Universidad Nacional Autónoma de México y Red para el Patrimonio Biocultural: Morelia, México, 2018.

33. Arnaiz-Schmitz, C.; Schmitzb, M.F.; Herrero-Jáureguib, C.; Gutiérrez-Angonesea, J.; Pinedab, F.D.; Montes, C. Identifying socio-ecological networks in rural-urban gradients: Diagnosis of a changing cultural landscape. Sci. Total Environ. 2018, 612, 625-635. [CrossRef]

34. Prigogine, I.; Stengers, I. Order Out of Chaos: Man's New Dialogue with Nature; Bantam New Age Books Eds: Flamingo, Canada, 1984.

35. Prigogine, I. El Fin de Las Certidumbres; Editorial Andres Bello: Santiago, Chile, 1996.

36. Naveh, Z.; Lieberman, A.; Sarmiento, F.; Ghersa, C.; Leon, R. Ecología de paisajes. In Teoría y Aplicación; Editorial Facultad de Agronomía Universidad de Buenos Aires: Buenos Aires, Argentina, 2002.

37. Naveh, Z. Ecological and cultural landscape restoration and the cultural evolution towards a post-industrial symbiosis between human society and nature. Restor. Ecol. 2007, 6, 135-143. [CrossRef]

38. Fischer-Kowalski, M. Society's metabolism. The intellectual history of materials flow analysis, Part I, 1860-1970. J. Ind. Ecol. 1998, 2, 61-78. [CrossRef]

39. Fischer-Kowalski, M.; Haberl, H. Tons, joules and money: Modes of production and their sustainability problems. Soc. Nat. Resour. 1997, 10, 61-85. [CrossRef]

40. Fischer-Kowalski, M.; Haberl, H. (Eds.) Socioecological Transitions and Global Change: Trajectories of Social Metabolism and Land Use; Edward Elgar Publishing: Northampton, MA, USA, 2007.

41. Sieferle, R.P. Cultural evolution and social metabolism. Geogr. Ann. Ser. B Hum. Geogr. 2011, 93, 315-324. [CrossRef]

42. Martínez-Alier, J. Conflictos ecológicos y justicia ambiental. Papeles 2008, 103, 11-27.

43. Balée, W. The Research Program of Historical Ecology. Annu. Rev. Anthropol. 2006, 35, 75-98. [CrossRef]

44. González de Molina, M.; Toledo, V.M. Metabolismos, Naturaleza e Historia. Una Teoría de las Transformaciones Socioecológicas; Icaria: Barcelona, España, 2011. 
45. Tyler, G. Ecología y Medio Ambiente; Grupo editorial Iberoamérica: Mexico DF, México, 1994; p. 867.

46. Herscovici, A. Historicidad, entropía y no-linealidad: Algunas aplicaciones posibles en ciencia económica. Revista Economía Politica 2005, 25, 277-294.

47. Georgescu-Roegen, N. La ley de la Entropía y el Proceso Económico; Fundación Argentaria/Visor: Madrid, España, 1996.

48. Subercaseaux-Ugarte, D. Implicancias ecológicas de la priorización económica en el paisaje cultural. Determinante de orden y sustentabilidad. Economía Sociedad Territorio 2013, 41, 181-226. [CrossRef]

49. Georgescu-Roegen, N. ¿Qué puede enseñar a los economistas la termodinámica y la biología? In De la Economía Ambiental a la Economía Ecológica; Aguilera Klink, F., Alcántara, V., Eds.; Barcelona: Icaria, España, 1994.

50. Naredo, J.M.; Valero, A. Desarrollo Económico y Deterioro Ecológico; Fundación Argentaria/Visor: Madrid, España, 1999.

51. Pimentel, D.; Pimentel, M. Food, Energy, and Society; CRC Press: Boca Raton, FL, USA, 2019.

52. Naredo, J.M.; Campos, P. La energía en los sistemas agrarios. Agricultura Sociedad 1980, 15, $17-114$.

53. Carpintero, O.; Naredo, J.M. Sobre la evolución de los balances energéticos de la agricultura española, 1950-2000. Historia Agraria 2006, 40, 531-554.

54. Muradian, R.; Martínez, J. South-North materials flow: History and environmental repercutions. Innov. Eur. J. Soc. Sci. Res. 2001, 14, 171-187. [CrossRef]

55. Wrbka, T.; Reiter, K.; Szerencsits, E.; Beismann, H.; Mandl, P.; Bartel, A.; Schneider, W.; Suppan, F. Landscape structure derived from satellite images as indicator for sustainable land use. In Operacional Remote Sensing for Sustainable Development. Proceedings of the 18 th EARSeL Symposium 11-15 May, 1998, Enschade, NL; Nieuwenhuis, G., Vaughan, R., Molenaar, M., Eds.; Balkem: Rotterdam, The Netherlands, 1998; pp. 119-127.

56. Fu, B.; Hu, C.; Chen, L.; Honnay, O.; Gulink, H. Evaluating change in agricultural landscape pattern between 1980 and 2000 in the Loess hilly region of Ansai County, China. Agric. Ecosyst. Environ. 2006, 114, 387-396. [CrossRef]

57. Ostrom, V.; Tiebout, C.M.; Warren, R. The organization of government in metropolitan areas: A theoretical inquiry. Am. Political Sci. Rev. 1961, 55, 831-842. [CrossRef]

58. Spire, A. El Pensamiento de Prigogine, la Belleza del Caos; Editorial Andrés Bello: Barcelona, Spain, 2009; $191 \mathrm{p}$.

59. D’Angelo, C. Marco conceptual para la ordenación de predios rurales. In Ordenación Territorial, Desarrollo de Predios y Comunas Rurales; Gastó, J., Rodrigo, P., Aránguiz, I., Eds.; Facultad de Agronomía e Ingeniería Forestal, Pontificia Universidad Católica de Chile, LOM Ediciones: Santiago, Chile, 2002; pp. 205-224. 